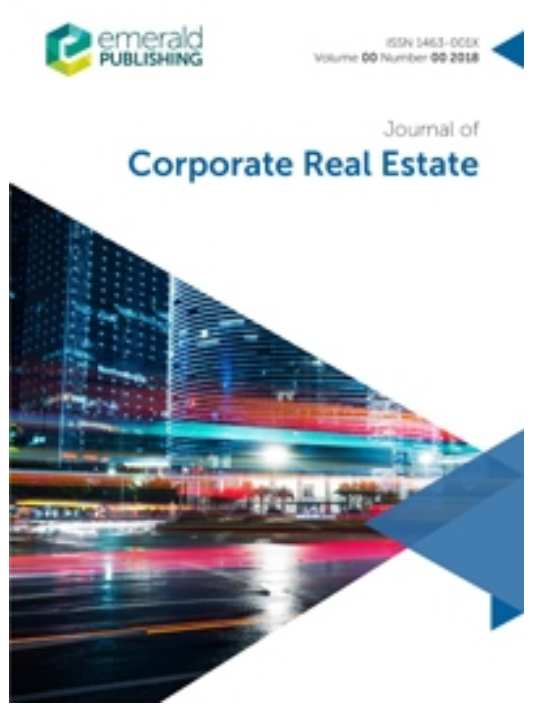

\title{
Future office layouts for large organisations: workplace specialist and design firms' perspective.
}

\begin{tabular}{|r|l|}
\hline Journal: & Journal of Corporate Real Estate \\
\hline Manuscript ID & JCRE-02-2020-0012.R3 \\
\hline Manuscript Type: & Research Paper \\
\hline Keywords: & $\begin{array}{l}\text { design firms, future office layouts, workplace, office layout, workplace } \\
\text { strategy, Australian context }\end{array}$ \\
\hline
\end{tabular}

\section{SCHOLARONE ${ }^{\text {M }}$ \\ Manuscripts}




\title{
Future office layouts for large organisations: workplace specialist and design firms' perspective.
}

\begin{abstract}
Purpose: Challenged by the effects of flexible workplace strategies, organisations are increasingly seeking flexibility and functional efficiency in their office space and its layouts. Once an organisation decides to change their office layouts, an office design firm or, a workplace strategist, can be employed to implement new workplace strategies. Understanding the client's requirements, as well as constraints, are key to creating an efficient office environment for occupiers. Since office layout arrangements have a significant influence on many important aspects of the organisation, design firms need to liaise with the client to determine the most appropriate design concept for their clients. In dealing with tenants over the years, design firms and workplace strategy firms have a broader understanding of what the common requirements are for tenants and landlords regarding requirements in workplace design. They have a good understanding of what clients' requirements were previously and how they have changed over time. Thus, design and workplace strategy firms have a better understanding of the requirements of future offices. This research, therefore, explores the factors which design firms consider when designing new office layouts and the nature of future offices from the design and workplace strategy firms' perspectives in the Australian context.
\end{abstract}

Design/methodology/approach: A qualitative study comprising semi-structured, in-depth individual interviews with eight internationally renowned design firms and workplace strategy consultant firms, involved in award winning office designs in Australia, was undertaken. All interview participants were professionals with extensive experience within the field. Qualitative data was analysed using a thematic approach, which adopted within case, and across case, analyses.

Findings: The results identified several major factors considered when identifying appropriate workplace strategies for large corporates. These included the existing and preferred culture of the organisation, the level of flexibility required, functionality and technology requirements, acoustic strategies, sense of community, the generation gap between employees, levels of brightness and colours of interiors and furniture choices. Participants believed future offices would be technology driven, community oriented, sustainability, health and wellbeing focused, smaller in size with satellite offices, such as co-working and office spaces.

Originality/value: The paper provides in-depth insights into how design firms and workplace strategy firms meet organisations' demands for physical spaces, and their main considerations in developing new workplace strategies in an Australian context.

Keywords: office layouts, organisations, design firms, requirements, future office layouts

Disciplines presented in the paper: Corporate real estate, Property, Built environment

\section{INTRODUCTION}


Workplaces are usually viewed as a cost centre rather than a driver of performance, with emphasis more often placed on factors such as increasing worker density and reducing total space requirements. Studies reveal that some organisations spend years preparing to change their office layouts. Office design specialists are involved to identify the most appropriate layouts for the organisation to align with their client's requirements. Understanding the nature of the business, work practices, corporate culture and other requirements of an organisation can help employers and office designers to offer the most suitable mix of the different types of spaces and the atmosphere of those spaces. Evidence suggests that architecture, interior design and furnishings provide a way to support - or even change - the employee perceptions of their workplaces and the away they work withing the workplace (Cagliano et al, 2011). There are researches in corporate real estate literature addressing the requirements, benefits and challenges of new office designs and layout arrangements. Most of the published literature is based on user perspectives, and in based on research undertaken in many different countries. Limited empirical research has been conducted to understand these issues from the design and workplace specialist consultant's perspective and very limited literature covers the Australian context. m

This research addresses this research gap by identifying the factors considered when designing new office layouts from the design and workplace strategy specialist firms' perspectives in Australia. This research is extended further to understand the nature of future offices required by tenants and landlords in the CRE sector in the Australian property market from the design and workplace strategy specialist firms' perspectives. The main research question is; what are the current considerations and the future expectations of office layouts in large organisations from the workplace strategy specialists' and design firms' perspectives?

Eight large, internationally renowned design firms and workplace strategy specialists were interviewed for this research and this paper presents their perceptions, the processes followed when changing office layouts and work practices, and the issues confronted when incorporating new layouts. Two research objectives were stablished prior to the interviews with the design and workplace strategy firms. These research objectives are:

1. To gain a deeper understanding of the main considerations in designing new office layouts and work practices from the design and workplace strategy specialist perspectives in the Australian CRE sector, and:

2. To identify the nature and characteristics of future corporate offices from the design and workplace strategy specialist perspectives in Australian CRE context.

\section{LITERATURE REVIEW}

Many organisations redesign, or change, their workplaces with the intention of creating a dynamic alignment between organisational goals and the spatial environment (Hassanain, 2006; Arge, 2005). However, such changes in their workplaces should be carefully planned to avoid any negative impacts on employees and the image of the organisation (Joroff et al. 2003). It is emphasised that flexible workplace practices may lead to success, only when organisational members, understand the purpose of such changes, use those facilities as intended; and are committed to continuous behavioural improvement (Erlich and Bichard, 2008; Joy, \& Haynes, 2011). Therefore, it is important to understand the factors that need to be considered when designing workplaces for client organisations to support achieving their expected outcome from those changes.

Typically, buildings were designed for a 9am to 5pm work pattern which mainly adopted 'Traditional' work practices in Scientific Management theory Szarejko and Trocka- 
Leszczynska, 2007). Hive, Cell, Combi, Den and Club (Szarejko and Trocka-Leszczynska, 2007) are the most common office layout plans used in Traditional work practices. Office environments and facilities have undergone gradual change, as working patterns have evolved to new ways of working, such as flexible and agile work practices (Laing et al., 1998). Most of these layout changes in the workplace come with new work practices; and, organisations expect several benefits from these changes in various ways. Integrated workplace strategy, which addresses client requirements such as aims of the proposed changes and how the changes contribute to the aims, is important for successful completion of a project (Barber et al., 2005; Bradley and Woodling, 2000; Duffy, 2000).

Gensler (2005) estimated that poorly designed workplaces could cost over 135 billion pounds every year in the British economy. Those cost could have been minimised if workplace have designed properly. Haynes et al (2005) identify the positive relationship between office layout and productivity. Gensler (2005) also identified the working environment could improve productivity by 19 per cent and employee satisfaction by 79 per cent in legal, media and financial sectors. He also recognised the relationship between working environment, recruitment, retention, productivity and ability to achieve it business strategy. Research based on 102 work settings in Sydney offices, Ilozor et al. (2002) revealed that more diverse office designs would increase employee's productivity. He further concluded that increased number of work settings would increase innovation in terms of fostering staff interaction.

Sustainability is another important factor that interests both tenants and landlords. Chinnakani et al., (2011) emphasised the importance of using intelligent on-off system for HVAC systems. Others recognised employees' preferences for thermal comfortability in their personal workspaces, with special air conditioning control facilities (Cho, S.H., et al, 2001). Excessive noise levels have been a concern of users in workplaces and designers are expected to use technologies to reduce noise levels in open plan layouts. Sound masking treatments have been a popular solution among users and designers, although it is an expensive solution. Horrall and Rosenberg (2006) found that stand-alone acoustic solutions could reduce the cost of multiple solutions, such as material selections for ceiling tiles, private office wall construction and workstation design. It would be interesting to see if design firms consider this issue beforehand, rather than after the issue arises.

Better communication, collaboration, and information sharing and knowledge integration are other key expectations tenants have from their workplaces. Innovative technologies, advanced information and communication technologies, globalisation of businesses, increase in team and project-based working practices, the emergence of flatter organisational structures, reorganisation of work activities and the emerging trend of knowledge-based activities are major expectations of workplace from the user perspectives (Saurin and Ratcliff, 2010; French and Jones, 2010; French and Wiseman, 2003; Irons and Armitage, 2003; Lizieri, 2003; Joroff et al., 2003; Fawcett and Rigby, 2009; French, 2001). However, there is little evidence in published literature, if design and workplace strategy consultants put the same emphasis on this when design new workplaces for large corporates in Australia.

Workplace design and physical office layout convey messages to employees and other stakeholders about an organisations values, ways of working and culture. It is not well known that design and workplace strategy consultants firm consider this in their design process. As organisational culture has a significant influence on the success of an organisation, it is not clear in existing literature how workplace strategy specialists' and design firms understand these changes and incorporate the changes into their designs (Mars, G.,2008; Miller, 2014; Morgan, \& Anthony, 2008; Rothe et al, 2011). However, there is limited academic 
literature about extent of office designers understand the importance of addressing these elements in their clients' design.

New workplace strategies would change the socio-spatial contract between employer and employee (Bell and Anderson, 1999). What this is to workplace strategy specialists, and how they address this relationship (Cameron \& Quinn, 2006) is not clear in property literature. Literature also highlighted the importance of making a great effort in getting employees involved during a move to more flexible workplace strategies (Binyaseen, 2010; Brunia, and Hartjes-Gosselink, 2009). Therefore, it was recommended to implement programmes with employees to help ease the transition. (Appel-Meulenbroek et al., 2011; Joroff et al., 2003). However, it is not clear in academic literature if design and workplace strategy specialist firms consider this as a part of the design strategy in Australian context.

Before implementing changes to a workplace, conducting experimentation with pilot activities with client, would be extremely useful (Lizieri, 2003; Duffy, 1999). Such pilot projects may provide valuable insights for implementation, thus limiting risks and helping to avoid "pitfalls" associated with layout changes (Schriefer, 2005; Earle, 2003). If there is a mismatch between the office environment and works happening in that environment, productivity losses are inevitable (Mawson, 2002.; Göçer et al., 2017;). However, majority of literature focusses on user perspectives and there is limited published evidence available in of design and workplace specialist consultant firm perspectives in Australian context.

Brill et al. (2001, p.19) identified the most important workplace features from designers' perspectives as;

1) Ability to do distraction-free solo work.

2) Support for impromptu interactions.

3) Support for meetings and undistracted group work.

4) Workspace comfort, ergonomics and enough space for work tools.

5) Workspace side-by-side work and "dropping into chat".

6) Located near or can easily find co-workers.

7) Workplace has good places for breaks.

8) Access to needed technology.

9) Quality lighting and access to daylight.

10) Temperature control and air quality.

However, this finding were 2001 which is about two decades old and US based. This research attempt to identify the considerations of workplace strategy specialists' and design firms focus on in the late 2010s and in Australia context for which no published evidence exists.

\section{Future offices:}

Office environment has been changed significantly over the last few decades. Due to the changing nature of business environments, the nature of office environment had to be changed too. Change of business environment are caused mainly by changes happening in the market, competition, new technology, workforce, workstyle, workplace, and; in organisational structures (Harris, 2015). There are opinions on how future workplace would look like in CRE sector in user perspectives. Harris, (2015) emphasised that changes in future offices would be mainly focussed on "software" of the organisation, which are; cultural, social and value systems and not the "hardware" side, such as desk, partition, layout or technology. Organisations will be looking at office space which gives opportunity to be more agile and connected with giving high flexibility and variety of choices (Halvitigala, and Reed, 2015). Harris, (2015) contradictory to his own argument above he believes that usage of high 
technology will be another key element in future offices. Regardless, the theoretical approaches of layout planning (Brooks, 1998; Stewart, 1985) separation of sections of buildings such as building structure, façade and fit outs would increase the adaptability of the building (Remøy, et al, 2011) and it would minimise possible challenges of future layout changes (Steen et al, 2005; Steiner, 2006). Remøy, et al, (2011) emphasised that adaptability cannot be predicted, thus allowing provision for change is a good solution.

Halvitigala and Reed (2015) believe that purpose-built campus style offices, serviced offices and multi-functional office spaces would be in high demand for future space requirements for some tenants. More space for socialisation, bigger floor plates for open plan and cellular space, higher vertical rises, communication booths and adaptable partitions would be requirements of future offices also (Markland, 1995). Diverse usage patterns will be encouraged more in future offices (Halvitigala and Reed, 2015). Fit-out solutions is another focus for future offices, while greater permeability of buildings to support new work patterns, such as co-working and shared facilities.

However, this literature was from the CRE and facilities management user perspectives, but very limited literature was available addressing this issue from the design and workplace strategy firm perspectives in Australia. Thus, another objective of this research was to understand the nature of the future workplace in the corporate sector from the design and workplace strategy specialist firms perspective.

\section{RESEARCH METHODOLOGY}

To obtain in-depth understanding of research problems, a qualitative research design was adopted. Qualitative methodology allows researchers to describe feelings and ideas, such as problems, experiences and challenges. Semi structured, face to face interviews were decided to be the most appropriate data collection method in this research.

Semi-structured interviews allowed participants to answer the questions freely and ensured a consistent coverage of the topics between the interviews. All interviews were conducted at participants' workplace or, their nominated place. The first part of the interview questions was about their work experiences, projects they have been involved in and their contributions. The second part of the interview was focused on interviewees attitudes, beliefs, experiences and predictions on research objectives. Interviews were focused on two major areas.

i. Main considerations in designing new office layouts and work practices.

ii. Nature of future office layout arrangements of large organisations.

Eight internationally renowned and award winning workplace strategy consultants and design firms in Australia were selected for the interview sample. All interview participants were high profile professionals with extensive experience in the relevant field. Individual, face to face semi structured in-depth interviews were conducted as the data collection method to explicitly discuss ideas, perceptions and experiences since the researcher is able to get physically and psychologically closer to the phenomenon (Perry, 1998). Selected firms have been involved in office layout redesign of large commercial buildings in Melbourne and Sydney in recent years. With these recent and past experiences of large office building redesign, these organisations would have a deep understanding of future office layout requirements for large organisations. All interviews were recorded and that transcriptions were made. Data were analysed using a thematic approach. with the use of within case, and across case, analyses (Creswell, 2009). 
Table 1 shows the profile of interviewees who contributed their extensive experience to this research.

Table 1: Profiles of interviewees.

\begin{tabular}{|c|c|c|c|c|}
\hline Interviewee & $\begin{array}{l}\text { Scale of } \\
\text { work }\end{array}$ & Position in organisation & $\begin{array}{l}\text { Experience } \\
\text { (years) }\end{array}$ & $\begin{array}{l}\text { Interview } \\
\text { duration }\end{array}$ \\
\hline Respondent 1 & International & $\begin{array}{l}\text { National Director - Australia \& New } \\
\text { Zealand }\end{array}$ & 15 & $45 \mathrm{~min}$ \\
\hline Respondent 2 & International & Director- Workplace strategy \& change & 7 & $55 \mathrm{~min}$ \\
\hline Respondent 3 & International & $\begin{array}{l}\text { Senior Consultant - Workplace \& } \\
\text { change strategy }\end{array}$ & 9 & $105 \mathrm{~min}$ \\
\hline Respondent 4 & National & $\begin{array}{l}\text { Workplace researcher, design } \\
\text { consultant and strategist }\end{array}$ & 16 & $50 \mathrm{~min}$ \\
\hline Respondent 5 & National & Director - Projects (Interiors) & 18 & $50 \mathrm{~min}$ \\
\hline Respondent 6 & International & Head of Design - Interiors design & 21 & $45 \mathrm{~min}$ \\
\hline Respondent 7 & International & Design consultant and strategist & 18 & $40 \mathrm{~min}$ \\
\hline Respondent 8 & National & $\begin{array}{l}\text { Pioneer of business culture } \\
\text { transformation \& contemporary } \\
\text { Australian workplace design }\end{array}$ & 19 & $50 \mathrm{~min}$ \\
\hline
\end{tabular}

(Source: Authors)

\section{RESULTS AND DISCUSSION}

\section{Main considerations in designing new office layouts and work practices.}

Design and workplace strategy firms explained the main factors they consider when designing office spaces. These factors identified by design and workplace strategy specialists firms are categorised in figure 1 and discussed below.

Figure 1: Main factors considered in determining appropriate layout structure.

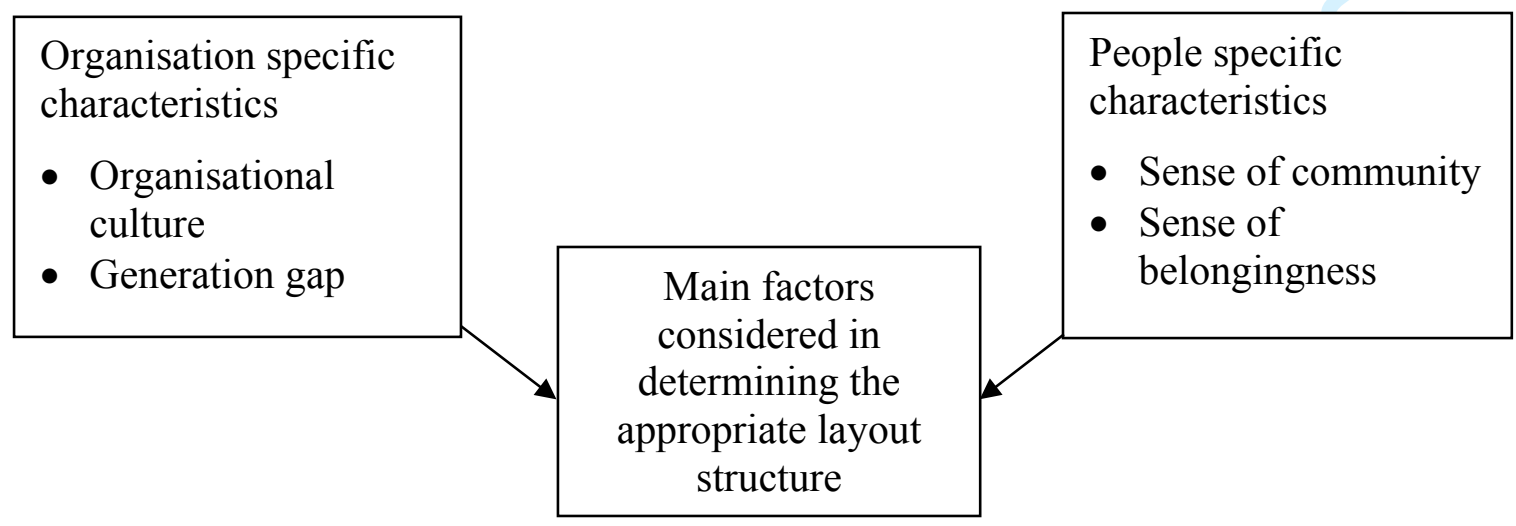


(Source: Authors).

\section{i. Organisation specific characteristics:}

a) Culture of the organisation

One of the main factors which need to be considered when designing a workplace is the culture of the specific organisation. Although some literature discussed behavioural changes following layout changes (Binyaseen Binyaseen, 2010; Brunia, and Hartjes-Gosselink, 2009), property literature did not emphasise the importance of integrating organisational culture into workplace designs. One interviewee revealed the relationship between organisational culture and office layouts: "Different layouts support different cultural dimensions" (Respondent 1).

This is important, since different layouts support different cultural dimensions. They further revealed that one of the main reasons for changing the existing layouts is to change their culture or, further establish their existing culture. Office spaces are designed to utilise the physical environment in a way that adds the most value to employer's objectives, enabling for choice on how much interaction they want. One interviewee emphasised;

\section{"organisational culture is not "one size fits all," and the physical layout should only be an extension of the culture, showcasing the values of the organisation." (Respondent 3)}

Interviewees identified two dimensions of corporate culture that may help organisations to understand appropriate office layout for them: interaction and autonomy. Interaction refers to the amount and intensity of face-to-face communication that is necessary to carry out their work while autonomy refers to the degree of individual choice regarding when, where and how work is undertaken as respondent 5 summarises:

"It's pretty clear often from the business goals and vision what their culture is at the moment, and we talk to them to find out what they want it to be. Sometimes they're close, and sometimes they're really far apart. We help them with change management to get their culture where they want it to be" (Respondent 5).

Changes in an organisation have implications for the existing organisational culture and work practices (Brunetto, 2001). New working strategies, such as flexible working arrangements, working from home, outsourcing and the use of technology, weaken the existing organisational culture (Hofstede et al., 2010a). The nature and type of work practices have significant implications for building design (Fairs, 2016; Tharp, 2009). 


\section{b) Generation gap}

Interviewees stated that many organisations have employees from four generations and workplaces are shared by these employees with different work experiences, work styles and expectations. Workplaces need to accommodate these variations and the near 50-year age gap amongst the employees. As per literature, Baby Boomers comprise $25 \%$ of the workforce, generation $\mathrm{X} 50 \%$, generation $\mathrm{Y} 20 \%$ and generation $\mathrm{Z}$ the remaining $5 \%$ of the workforce, all have different technology skills, work practice preferences and psychological needs which should be incorporated into office layout designs. Interviewees indicated that they obtain all information about employee demographics before designing workplaces and, to date, the literature has not highlighted this generation gap design factor. "Different age groups in the workforce have different technology skills, work practice preferences and psychological needs, and such needs should be incorporated into office layout designs" (Respondent 2).

Interviewees emphasised that modern office layouts provide the opportunity to have a better mix of spaces for different generations by removing physical and hierarchical barriers to encourage collaboration and knowledge transfer. They employed strategies to address the generational gap in workplace design by providing several arrangements, including:

1. Providing flexible work settings that employees can choose from based on their needs.

2. Providing collaboration spaces for generations $\mathrm{X}, \mathrm{Y}$ and $\mathrm{Z}$ and; personal spaces for Baby Boomers.

3. Improving technology tools to support the way in which Gen $\mathrm{X}, \mathrm{Y}$ and $\mathrm{Z}$ are accustomed to working.

4. Creating spaces that provide good access to support staff and resources for Baby Boomers.

5. Creating spaces that provide access to mentoring and learning experiences for Gen $\mathrm{X}$, $\mathrm{Y}$ and $\mathrm{Z}$.

6. Future proofing the space to facilitate more flexibility and remote working when Gen $\mathrm{Y}$ and $\mathrm{Z}$ become the highest portion of the workforce.

Overall, all participants suggested that efficient space layouts would have spaces that are suitable for different employees' different expectations. For example, there are 'retro-tech' areas for traditional workers and 'high-tech' areas in interactive areas to support young employees.

\section{ii. Space specific characteristics: \\ a) Flexibility}

For these interviewees, flexibility is the biggest and most commonly requested requirement of most clients. Erlich and Bichard (2008) and Joy \& Haynes (2011) found this requirement is mostly predicated on the reality that organisations do not know where their business would be in the future, due to the changes in their business strategies, working strategies and technology and future growth. Therefore, clients want their office layout to be flexible enough to adjust for, currently unknown future circumstances. One interviewee explained:

"You actually need to design it in many ways, with many settings, because how you might work now might be different to how you might work in two years' time, and that staff numbers are going up and down. So if a space is indicative for the shrinking and the grand growth of staffing numbers and how people work" (Respondent 7). 
Organisations require flexibility in many areas such as, the partitioning used, flexible meeting rooms, adjustable table and chairs and flexible working schedule. It is suggested that flexibility is the theme for many office layout designs and flexibility in building services were required to increase the density of offices. All participants suggested, a modular approach to office designs to provide flexibility for changes in function, movement or organisational growth is commonly adopted.

\section{b) Functionality}

Interviewees highlighted that some organisations provided lockers which were not big enough for employees to put their belongings into. If lockers are not big enough to store their belongings, the lockers are not functional enough. Interviewees indicated that electronic locking systems are more functional to operate than manual padlocks. They explained that allocating zones for each department is more functional than asking employees to work anywhere in the building. Staff in the same department, or team, would be available in that zone for easy collaboration. In addition, this arrangement helps each department to maintain their sub culture. As one workplace strategy organisation explained what they did with a client:

"Parts of the business get assigned work stations, and they can sit in the same place every day, but this part of the business has to operate under a flexi-desk type arrangement, then you've got sort of dichotomy across the business. So, there's 20 desks allocated for the accounts department and it might be because those staff never leave the office that there's not a ratio applied to that, so if there's 20 staff there will be 20 desks. But the design principles remain the same in that you need to pack up your stuff at the end of the day and put it in your locker" (Respondent 1).

All participants considered functionality as a key consideration of workplace designing.

\section{iii. Service specific characteristics:}

\section{a) Technology}

All interviewees shared a common view that changes in building specifications and configurations occur at a much slower pace than changes in work practices and information and communication technology which is confirmed in the literature (Bradley and Hood, 2003). Two main technology changes that have emerged in the past decade, high speed external fibre networks and mobile and wireless technology, affect the way people work as well as the design of office layouts. Therefore, office layout designs are often designed, or redesigned, to ensure the building is capable of introducing supporting technologies such as wireless networks and adequate communications connectivity to support the enhanced technology. Design firms believe that the latest ICT facilities help organisations to attract, and retain, high skilled new generation workers. Many organisations increasingly rely on highly motivated, young individuals who are enabled by technology. "Modern workplaces are designed to support knowledge transfer and connectivity among new generation of employees" (Respondent 7). Three of the interviewees (3, 4 and 7), also stated that they consider the wellness of employees as well by connecting "IoT (Internet of Things) systems to sit/stand desks" (Respondent 4).

All participants mentioned that technology is one of their key considerations when designing a workplace for their clients.

\section{b) Acoustic strategies}


Interviewees suggested that acoustic issues frequently arise in open plan layouts, which can be overlooked in the initial design phases, as some organisations focus on the aesthetics aspects of the space. Installing sound absorption technologies such as acoustic screens which would adversely increase acoustic issues in open plan offices (Respondent 1). If there are no partitions or screens, staff are aware and avoid making loud noises, however if there are partitions, they talk louder not realising that partitions do not reach the ceilings. The end result is more noise is created than when there are no partitions provided. Some design and workplace strategy firms believed that noise is a good thing as one interviewee explained:

"But the flip side to that is what noise means? That people are connecting, collaborating. No one thinks like that, everyone is going, oh it's just too noisy, it is noisy because people are actually talking to each other. Then you correlate that to email volumes going down. I suggest that's exactly what you want for your business" (Respondent 2).

Design firms take a range of acoustic goals into consideration in modern office plan environments, including controlling noise in common areas, establishing some privacy and sound absorption for employees at their desks and providing private spaces for confidential discussions (Respondent 2). In addition, soundproof walls, panel absorbers on the side walls and associated floor materials such as needle-punched carpets are used in modern office designs to decrease sound levels. Furthermore, 'sound masking systems' which consist of a series of speakers that generated electronically generated unobtrusive music to cover background noise are commonly used in modern office designs. In addition, office furniture and equipment can be strategically placed to minimise its sound impact on neighbouring workstations.

All participants confirmed that acoustic strategies is one of their key considerations when designing a workplace for their clients.

\section{iv. Aesthetic specific characteristics:}

a) Bright and interior colour

All interviewees shared the common view that choosing the right colour is an important decision in interior designs. It was suggested that colour choices not only a just personal preference, but they can influence occupiers' moods, emotions, perceptions by attracting attention, both consciously, and subconsciously. Furthermore, colour can brand a space, signifying what interactions are to occur in those areas. Therefore, choosing the right colour and brightness would give a good impression of organisation and its culture on their employees, as well as customers. Design and workplace strategy firms emphasised that they used different colours for the areas allocated for different activities as shown below:

Blue - often associated with stability, it communicates a reliable outlook whilst boosting relaxation and intellectual thoughts. It is used in collaborative areas in modern offices.

Red - aiding with employee heavy concentration. It is used in areas where concentration is needed.

Yellow - used for areas where occupiers are required to be more creative and innovative

Green -used for areas that need a strong sense of balance, calm, warmth and reassuring feelings. 
White - is avoided in modern office environments as it promotes feelings of tension and discomfort. (Respondent 7)

\section{b) Furniture choices}

Appropriate selection of furniture is an important contribution employees' comfort, health and wellbeing, and it has an impact on organisational ergonomics. Material, colour, comfort, adjustability are the main criteria when selecting furniture for modern office spaces.

Soft seating on wheels, mobile tables and movable privacy screens are commonly used to allow participants to create a collaborative meeting space easily. Adaptable, convertible furniture such as standing desks, movable desks, convertible standing desks, communal desks and leaning desks are used to allow occupiers to transform workstations into an opportunity to inspire brainstorming sessions and promote effective discussion among employees. Poor choice can hinder engagement, as respondent 7 noted: "Furniture choice is very important. I had meetings around enormous boardroom tables that actually stopped conversations happening and stopped connection forming" (Respondent 7).

Only three out of eight interview participants mentioned that they considered furniture choice for their client as a part of office design.

\section{v. People specific characteristics: \\ a) Sense of community}

Interaction between employees is important, and all interviews revealed that social places for employees including larger atria, lobbies and cafés, where employees and socialise and work, are considered as amenities that increase the sense of community. It was suggested that; "about a four and a half minute waiting time at the coffee machines is the ideal time for employees to start conversation and get to know each other" (Respondent 1).

In addition, high quality buildings often have amenities such as gyms, childcare facilities, banks, ATMs, convenience stores, small supermarkets, community gardens, games rooms, indoor bicycle and scooter tracks, on-site shower facilities, as well as, break away rooms for relaxation and contemplation. Interviewees stated that these facilities create a more home like environment for occupiers, and enhance their physical and physiological connectivity with the building while providing the competitive edge to such properties.

\section{b) Sense of belonging}

Though the literature did not highlight sense of belonging, it was revealed that modern designs aim to provide employees with this attribute in new work environments, as stated by Respondent 1. "Fostering better sense of belonging (Nesting) has been found in many cases to enhance wellbeing and allow a person to create a sense of security" (Respondent 1).

Participant emphasised that they incorporated several specific elements into office spaces to create an optimistic sense of belonging in workplace. These features include:

1. Creating welcoming entrances with visible hosting.

2. Offering video-conferencing configurations that allow remote participants to connect.

3. Designing informal areas for socialisation, both in person and virtually. 
4. Creating spaces that provide occupiers choices and empower them to work alone or together.

5. Including spaces beyond the lobby that reinforce the culture of the organisation.

6. Using modern technology to help employees feel connected and informed.

7. Designing areas that allow workers to control their sensory stimulation.

8. Offering places that are calming, through the materials, textures, colours, lighting, and views.

Six out of eight participants mentioned that sense of belonging is one of their main considerations when designing a workplace for clients.

Table 2 shows the number of interview participants who mentioned the factors discussed above.

Table 2: No. of participant discussed-Factor considered in designing.

\begin{tabular}{|l|c|}
\hline \multicolumn{1}{|c|}{ Factor } & $\begin{array}{c}\text { No of participant } \\
\text { discussed }\end{array}$ \\
\hline Culture of the organisation & 8 \\
\hline Flexibility & 8 \\
\hline Functionality & 8 \\
\hline Technology & 8 \\
\hline Acoustic strategies & 8 \\
\hline Sense of community & 6 (except3 \&5) \\
\hline Sense of belonging & 8 \\
\hline Bright and interior colour & 3 (only 7, 1\&3) \\
\hline Furniture choices & 8 \\
\hline Generation gap & \\
\hline
\end{tabular}

(Source: Authors).

\section{Future office layout arrangements of large organisations}

The interviewees discussed how future physical office environments would look considering the changes that occur due to internal organisational pressures, as well as external changes, which are beyond the control of organisations. None had a clear idea about how future office spaces would look, as a result of the fast changing nature of technology, work practices and the changes in the corporate culture of organisations. However, they discussed possible improvements they would like in future office environments which are analysed below.

\section{Technology driven spaces}


All interviewees believed future office environments would be strongly influenced by advances in technology. People would be more mobile than ever before and workplaces would only be used for collaborative purposes. Desks and large computer screens would gradually disappear.

Therefore, future workplaces will rely on big data, with an expectation to see the rise of the intelligent workplace that monitors its workers' environment, mood, wants, needs and performance. Future office environments will use more sensory data to better understand employee performance dynamics. Interviewees suggested people's involvement would mainly focus on critical thinking and problem exercises, as artificial intelligence computing will dominate future work environments. The importance of incorporating such changes into office utilisation strategies was emphasised.

\section{Virtual offices}

Remote working, with the use of cloud work environment, would be become commonplace allowing employees to cultivate their own work environments and schedules to best suit their needs. Easy WiFi access, smartphones, conferencing and advanced communication software would foster an office setting without employees being in the office physically. However, they perceived that virtual offices could get to a certain point of success only. As existing workplaces have evolved considerably to date, change would not go too much further. Though many studies discussed technological advancement (Rothe et al., 2011; Knight Frank, 2017), the virtual office concept was not highlighted.

Overall, interviewees emphasised that these plans would vary a lot, by organisation and department, as the design of the office space should be tailored to the nature of employees' work and their work patterns. All participants mentioned that large corporates would be heading towards to virtual offices to some extent.

\section{More community environments}

Future offices will focus on providing more community environments rather than more formal work environments. Given that people are busy with their day-to-day activities and, most services and facilities available through virtual resources, people are disconnected to each other. Future workplaces, therefore, might fill those gaps by providing more connected and community environments for employees. Some literature discussed social spaces in workplaces (Halvitigala, and Reed, 2015) but not as an entire community environment.

Interviewee (Respondent 8 ) believed that workplaces with collaborative spaces will be more important in future, though advanced technology will enable virtual offices. He believed that smart decisions and dynamic solutions mostly emerge when employees work together to resolve problems. Seven out of eight interview participants mentioned community as a feature of future offices.

\section{Sustainability focus}

All the interviewees believed that future workplaces would focus more on environmentally sustainable features. "Organisations would provide more environmental friendly work facilities and employees would be encouraged to use environmentally friendly ways of working" (Respondent 2).

Large organisations have started using natural light, natural air, recycled water, recycled papers and products which create minimum carbon foot print and future office layouts may be 
designed for zero paper usage and future workplaces would further enforce these practices (Respondent 2).

\section{More diversity and amenity}

Seven out of eight interviewees believe future workplaces would have more diverse work settings to support day-to-day activities highlighted by Respondent 3:"The workplace would be surrounded by many amenities which people need, such as; libraries, childcare centres, gyms, medical centres, cafés, restaurants, grocery shops and banks" (Respondent 3).

The interviewees suggested that the 'three minute worker' concept, which focuses on providing occupants to have their main requirements within a three-minute work, would be a common concept for most office buildings in the future.

\section{Hoffice}

Interviewees suggested that the 'hoffice' will be a popular concept among knowledge-based industries. "Hoffice is a concept where people offer out their own home as a co-working space for certain days or certain hours of the week" (Respondent 1). In such environments, selectively invited people would work together in a small group. The ability to avoid travelling long distances to the office and to collaborate in convenient, familiar locations are the main benefits of such environments. It was suggested that Hoffice work environments would be more common in the future, however this concept was not discussed in any literature reviewed. Only two out of eight interview participants mentioned this as a possibility for future offices.

\section{Creativity}

All interviewees commented positively about creativity; "future office environments would create environments for more collaboration, problem solving skills and creativity (Respondent 4). Literature discussed collaboration, teamwork and quick problem-solving ability relation with agile working but this has not been highlighted as creativity. Different features, such as creative walls and mapping walls will be common in most offices. In addition to collaboration within the organisation, the trend of co-working which involves different organisations sharing office space to boost creativity and energy is developing currently, and interviewees suggested that co-working will be more common in future. Six out of eight interview participants mentioned future office design would be mainly focussed on creativity.

\section{Health and well-being}

All eight interviewees focus on employee health and well-being in future office designs, as employees are the most important asset for organisations. Physical movement is highly encouraged, and office furniture would accommodate these requirements, such as adjustable desks. "Office layouts and interior designs will be increasingly focusing on employees physical and psychological wellbeing. Simple step like encouraging hight adjustable table to work standing; locating printer, kitchen within a reasonable distance." (Respondent 1)

Meel and Vos (2001) believe employees' emotional and mental states will have high importance when designing future office layouts. More specifically, Biophilic office design, which is an innovative way of designing office environments, would be popular in the future. Greenery and natural light are the two main themes of in biophilic offices which would help to 
put employees closer in touch with nature, to reduce their stress and open creative thought patterns.

\section{Smaller buildings and Satellite office}

Interviewees believed the size of office spaces would shrink further in future due to advances in technology, and changing work practices and organisational culture. Single large office spaces would be replaced by a number of small satellite offices which are based on the nature of job and the location of employees. However, the importance of having procedures to keep all employees connected with the organisation, was emphasised in the interviews. Interviewees noted that traditional workspace would disappear in the workplace strategy as Respondent 7 stated: "Satellite offices would also be popular with organisations who have mobile staff" (Respondent 7).

However, five out of eight interview participants mentioned smaller and satellite offices become more popular between both employers and employees. Table 3 shows the number of interview participants who mentioned above discussed factors.

Table 3: Factors in Future office designs and participants

\begin{tabular}{|l|c|}
\hline \multicolumn{1}{|c|}{ Factor } & $\begin{array}{c}\text { No of participant } \\
\text { discussed }\end{array}$ \\
\hline Technology driven spaces & 8 \\
\hline Virtual offices & 8 \\
\hline More community environments & 7 (except 6) \\
\hline Sustainability focus & 8 \\
\hline More diversity and amenity & 7 (except5) \\
\hline Hoffice & 2 (only 1\&7) \\
\hline Creativity & 6 (except 3 \&7) \\
\hline Health and well-being & 8 \\
\hline Smaller buildings and Satellite office & 5 (except 2, 6 \&8) \\
\hline
\end{tabular}

\section{SUMMARY AND CONCLUSION}

The main research question of this paper was to identify the factors consider when designing new office layouts and the nature of future offices from the design and workplace strategist firms' perspectives. To achieve the main aim, two research objectives were developed. They were;

1) to understand main considerations in designing new office layouts and work practices, and,

2) to identify possible characteristics of corporate offices in the future.

In respect of objective 1, this research identified organisations' main considerations in designing new office layouts and work practices. Flexibility, functionality, advanced technology, reduced noise level, improved organisational culture, improved sense of 
community and sense of belongingness, addressing the generation gap, interior colour and furniture choices were identified and established as key client requirements.

In respect of objective 2, we found that design and workplace strategy specialist firms believe that characteristics of future workplace would be more technology driven and with greater emphasis on sustainability features. They also emphasised that Virtual offices, greater focus on employee physical and psychological wellbeing, more creative, community oriented and diverse workstations would be some other features of large office buildings in the future.

The results reveal that office space designers do not consider office spaces as just a means of keeping the employees dry and warm. Instead, they view the physical office space as a means of reinforcing the corporate culture, improving organisational performance and employee productivity and attracting new talent to the organisation.

\section{PRACTICAL IMPLICATIONS}

This research has implications for industry and academics, as it provides an in-depth understanding of workplace specialists' and design firms' perceptions of future requirements from office spaces. It also illustrates what they look at when designing office spaces for large corporates. It demonstrates the need to consider how the office environment should align with the physical and psychological needs of the organisation and its employees. There is very limited published literature available addressing these issues from the design and workplace strategic specialists' perspectives; and, in the Australian context. Therefore these findings have practical application to professionals involved in human resource management and the design, management, development and valuation of office buildings.

\section{LIMITATIONS OF THE RESEARCH}

The main limitation of this research is the data collection was undertaken in Melbourne and Sydney only. Even though, most firms operate nationally and internationally, the findings would have been more generalisable if could collect data from other states and territories too. The number of interviewees was another limitation. All interview participants are from large firms and therefore this research did not represent the perceptions of small and medium scale firms.

\section{SUGGESTIONS FOR FUTURE STUDIES}

There could be significant impact on workplace design due to the COVID-19 pandemic. This is an interesting area for future research to understand that how the workplace was influenced by this unexpected health crisis. This study mainly focused on workplace design workspace for large corporate organisations. There is opportunity for future research to understand what the main considerations are when designing workspaces for small and medium sized organisations.

\section{REFERENCES}

Appel-Meulenbroek, R., Groenen, P. and Janssen, I. (2011), “An end-user's perspective on activity-based office concepts”, Journal of Corporate Real Estate, Vol. 13, No. 2, pp. 122-135.

Arge, K. (2005). “Adaptable office buildings: theory and practice”, Facilities, Vol.23, No. 3, pp 119-127 
Barber, C., Laing, A., \& Simeone, M. (2005). "Global workplace trends: A North American and European comparison", Journal of Corporate Real Estate, Vol. 7, No.3, pp 210-221

Bell, S. M. and Anderson, M. (1999). "Workplace solutions", Journal of Corporate Real Estate, Vol. 1, No. 4, pp 349-360

Binyaseen, A. M. A. (2010). “Office layouts and employee participation”, Facilities, Vol. 28, No.7, pp 348-357

Bradley, S. and Woodling, G. (2000). "Accommodating future business intelligence: new work-space and work-time challenges for management and design", Facilities, Vol. 18, Issue: 3/4, pp.162-167

Bradley, S and Hood, C. (2003). "Delivering minimalist workplaces that improve corporate agility", Journal of Facilities Management Vol. 2, Iss. 1, (2003): 68-84.

Brill, M., Weidemann, S. and The BOSTI Associates (2001), Disproving Widespread Myths about Workplace Design, Kimball International, Jasper, IN

Brunia, S. and Hartjes-Gosselink, A. (2009). Personalization in non-territorial offices: a study of a human need. Journal of orporate Real Estate, Vol. 11, No.3, pp 169-182.

Cagliano, R., Caniato, F., Golini, R., Longoni, A. and Micelotta, E. (2011) "The impact of country culture on the adoption of new forms of work organization", International Journal of Operations \& Production Management, Vol. 31 No. 3, pp.297-323

Cameron, K. S., \& Quinn, R. E. (2006). Diagnosing and changing organizational culture: Based on the competing values framework. San Francisco: Jossey-Bass.

Chinnakani, K., Krishnamurthy,A., Moyne, J., and Gu, F., (2011), Comparison of energy consumption in HVAC systems using simple ON-OFF, intelligent ON-OFF and optimal controllers. Power and Energy Society General Meeting, 2011 pp. 1-6.

Cho, H.S., Kim,W.T., and Zaheer-UddinThermal, M. (2001). Characteristics of a personal environment module task air conditioning system: an experimental study, Energy conversion and management, 42 (8), pp. 1023-1031

Duffy, D. F. (1999). "Mind the gap”, Journal of Corporate Real Estate, Vol. 1, No. 4, pp 377387

Duffy, F. (2000). "Design and facilities management in a time of change", Facilities, Vol. 18, No.10, pp 371-375

Earle, H. A. (2003). "Building a workplace of choice: Using the work environment to attract and retain top talent", Journal of Facilities Management Vol. 2, No.3, pp 244-257

Erlich, A. and Bichard, J. (2008). "The Welcoming Workplace: designing for ageing knowledge workers", Journal of Corporate Real Estate, Vol. 10, No. 4, pp 273-285.

Göçer, Özgür \& Göçer, Kenan \& Ergoz-Karahan, Ebru \& İlhan, Iş11. (2017). Exploring Mobility \& Workplace Choice In A Flexible Office Through Post-Occupancy Evaluation. Ergonomics. 61. 1-40. 10.1080/00140139.2017.1349937.

Halvitigala, D, and Reed, R., "Identifying adaptive strategies employed by office building investors", Property Management Vol. 33 No. 5, 2015

Gensler (2005). These four walls: The real British office. London.

Harris, H., () "The changing nature of the workplace and the future of office space" Journal of Property Investment \& Finance Vol. 33 No. 5, 2015 
Hassanain, M. A. (2006). "Factors affecting the development of flexible workplace facilities", Journal of Corporate Real Estate, Vol. 8, No.4, pp 213-220.

Haynes, B. P. (2008). "The impact of office layout on productivity", Journal of Facilities Management, Vol. 6, No. 3, pp 189-201.

Meel, J., and Vos, P., (2001) "Funky offices: Reflections on office design in the "new economy", Journal of Corporate Real Estate,Vol. 3 Issue: 4, pp.322-334,

Horrall, T., and Rosenberg C., (2006) "The role of sound masking treatment in the value engineering of office designs", The Journal of the Acoustical Society of America, Vol.119(5), pp.3351-3351

Ilozor, Ben Dozie; Love, Peter ED; Treloar, Graham. "The impact of work settings on organisational performance measures in built facilities", Facilities Vol. 20, Iss. 1-2, (2002): 61-67.

Jo, J. H., \& Gero, J. S. (1998). "Space layout planning using an evolutionary approach", Artificial Intelligence in Engineering, Vol. 12, No. 3, pp 149-162.

Joroff, M. L., Porter, W. L., Feinberg, B. and Kukla, C. (2003). “The agile workplace”, Journal of Corporate Real Estate, Vol. 5, No. 4, pp 293-311.

Joy, A., \& Haynes, B. P. (2011). "Office design for the multi-generational knowledge workforce", Journal of Corporate Real Estate, Vol. 13, No. 4, pp 216-232.

Lizieri, C. (2003). "Occupier requirements in commercial real estate markets", Urban Studies, Vol. 40, No. 5/6, pp 1151-1169.

Markland, M. (1998). "The future of the office building”, Facilities, Vol. 16, No. 7, pp 192197

Markland, M., (1995), "The future of the office building", Facilities, Vol. 13 Issue: 3, pp.1521

Mars, G. (2008) Innovation: Corporate cultures and the use of space: an approach from Cultural Theory. The European Journal of Social Sciences. Sep2008, Vol. 21 Issue 3, p185-204. 20p. 2 Diagrams, 4 Charts.

Mawson, A. ( 2002), "The Workplace and its Impact on Productivity", Vol. 4, Advanced Workplace AAAssociates, London, Publication No. 8, available at: www.occupier.org.

Miller, N. G., (2014), "Workplace trends in office space: implications for future office demand", Journal of Corporate Real Estate, Vol. 16 Issue: 3, pp.159-181

Morgan, A., \& Anthony, S. (2008). "Creating a high-performance workplace: a review of issues and opportunities", Journal of Corporate Real Estate, Vol. 10, No. 1, pp 27-39

Remøy, H., Jong, P.D., and Schenk, W., (2011), "Adaptable office buildings", Property Management, Vol. 29 Issue: 5, pp.443-453

Rothe, P., Lindholm, A., HyvÃ ๆnen, A. and Nenonen, S. (2011). "User preferences of office occupiers: investigating the differences", Journal of Corporate Real Estate, Vol.13, No.2, pp 81-97

Schriefer, A. E. (2005). "Workplace strategy: What it is and why you should care", Journal of Corporate Real Estate, Vol.7, No.3, pp 222-233 
Steen, J., Blombergsson, M. and Wiklander, J. (2005). "Useful buildings for office activities", Facilities, Vol.23, No.3, pp 176-186

Steiner, J. (2006). "The art of space management: Planning flexible workspaces for people", Journal of Facilities Management, Vol.4, No.1, pp 6-22.

Stewart, T. (1985). “Ergonomics of the office”, Ergonomics, Vol.28, No.8, pp 1165-1177.

Sullivan, K. (1996), "Changing technology and forecasting office space requirements", Property Management, Vol. 14 No. 1, pp. 24-29.

Szarejko, W. and Trocka-Leszczynska, E. (2007). “Aspect of functionality in modernization of office buildings", Facilities, Vol.25, No.3, pp 163-170. 